In ending I would submit that the course of events in an attack of Raynand's disease, so far at least as they bear upon the subject matter of these notes, is as follows: 1. A disturbance of the vaso-motor and katabolic nerves of such a nature that the normal processes of katabolism are interfered with. 2. A consequent retardation of the processes of metabolism with an accumulation of one or several intermediate waste products-amongst them uric and oxalic acids. 3. An oxalic acid " storm," characterised by a free excretion of oxalate of lime together with specific constituents of the blood, this excretion of blood-constituents being a direct effect of the action of the oxalic acid or its lime salt.

I am aware that sufficient evidence has not been brought forward to render these propositions absolutely convincing. But the fact of the association of an excessive excretion of oxalates with hæmaturia or hæmoglobinuria is beyond doubt, and the pathology of both Raynaud's disease and paroxysmal hæmoglobinuria is in such a condition that any fact which may perhaps lead to a better and more exact knowledge of the morbid processes at work is worthy of full examination.

\section{NOTE ON THE VALUE OF A SATURATED SOLUTION OF EPSOM SALTS IN THE TREATMENT OF ACUTE DYSENTERY.}

BY A. W. D. LEAHY, F.R.C.S.

SURGEON, INDIAN MEDICAL SERVICE ; OFFICIATING RESIDENCY SURGEON, HYDERABAD.

For many months past I have been in the habit of using sulphate of magnesia as a remedy in the treatment of cases of acute dysentery, and have been so much impressed with the successful results which have attended its use that $I$ feel it is only right to lay them before my profes sional brethren. The classical remedy for years past that has been almost universally prescribed in treating acute dysentery is, as is well known, powdered ipecacuanha, and probably in no country where this disease is met with is the prejudice in favour of this drug more deeply rooted than in India. All those army medical officers whose good fortune it was to have been enabled to attend the course of lectures on Military Medicine that were delivered by Professor J. C. Maclean at Netley must remember only too well with what eloquence he impressed upon their memories the specific properties of ipecacuanha as the remedy par excellence for acute dysentery, and will doubtless further remember the striking clinical cases he described to them in support of his views regarding the magical action of this drug. The majority of army surgeons meet with, and have to treat, their first cases of acute dysentery in India, and some, like myself, may have felt a considerable amount of disappointment in their early experience of the value of ipecacuanha In India the treatment of acute dysentery by the administration of large doses of ipecacuanha is looked upon as the only certain and reliable method of treatment we have and a well-known retired Indian medical officer and physician, possessing extensive clinical knowledge of the disease, writes thus concerning it: ${ }^{\text {_ }}$ "I Ipecacuanha in large doses may be said to fulfil many important indications. It produces all the benefits that have been ascribed to blood letting without robbing the system of one drop of blood all the advantages of mercurial and other purgatives without their irritating action; all the good results of antimonials and sudorifics without any of their uncertainty all the euthanasia ascribed to opium without masking, if not aggravating, the disease whilst the mischief is silently accumulating within. Thus we possess in ipecacuanha a non-spoliative antiphlogistic, a certain cholagrogue and unirritating purgative, a powerful sudorific, and a harmless sedative to the heart and the muscular fibres of the intestines." That ipecacuanha in the treatment of acutedysentery possesses many of these attributes and properties $I$ admit, but there is another side to the picture as represented by the objections that have been urged against the administra-

I Article on Dysentery in Quain's Dictionary of Medicine, by Joseph wart, M.D., F.I.C.P., \&c. Kondon, 1885. tion of large doses of the drug in this disease. A little further on in the same valuable article Dr. Ewart observes: "The objections which have been urged arainst large doses of ipecacuanba in dysentery are-first, its 'depressing in fluence' kept up by nausea and vomiting; and, secondly, that it is liable to set up nncontrol/able vomiting." These objections are, to my mind, very serious ones, and detract considerably from the value of the method of treatment. The depressing influence of the drug when given in large doses is probably familiar to those who have used tho remedy, and in cases where its administration is fol lowed by violent and persistent vomiting this depression may be increased to an alarming extent. Further, when the vomiting occurs, it follows clusely npon the swallowing of the drug, which, being thus ejected, is prevented from exerting its valuable effects upon the dise:sed mucous membrane of the intestines, while the patient's vital powers are depressed by the violent vomiting and retching, without any good impression being made upon the disease itself. Acute dysentery is in itelf a diseace accompanied by considerable nervous depression, and any remedy that tends to in any way increas this depression is objectionable. have known several cases in which the administration of one large dose (thirty grains) of ipecacuanha in acute dysentery has been followed by violent persistent vomiting, and such continuous irritaljility of the stomach as to completuly prevent the retention of anything within that viscus while the dysenteric symptoms continued unabated. Influenced by such cases as these, and also by the fact that in cases where large doses of ipecacuanha are tolerated by the patient there is frequently a sense of the most trying and terrible nausea, 1 commenced treating cases of acute dysentery by the administration of a saturated colution of Epsom salts. My aitention was first directed to the value of this drug in dysentery by my old friend Dr. J. Anderson, at present one of the physicians to the Seamen's Hospital, Greenwich. When speaking to me about it, he referred me to a short paragraph in a work upon Therapeutics by an American author, who on p. 564 writes as f.llows: "The most efficient treatment of acute dysentery is by the administration of sulphate of magnesia. It is especially adapted to the acute stage, where there are fever, pain, tenesmus, and stools of mucus and blood. It lessens the hyperæmia and causes fæcal evacuations, with the result of relieving the pain and the distressing straining." I append a table of 95 cases, mostly of out-patients, treated during the present year in the Residency and Afznl Gang Hospitals respectively. The stools consisted in each case, with one exception, of blood and slime. Recovery ensued in all, except Cases 14 and 30, which terminated fatally.

It is administered as follows:- "Take a sufficient quantity of sulphate of magnesia to saturate seven fluid ounces of water, and to this saturated solution add one ounce of diluted sulphuric acid. The dose of this is a tablespoonful every hour or two in a wineglassfal of water until it operates. Sulphate of morphia may be combined with it, or starch enemata with laudanum may be employed." I have now treated 103 cases of acute dysentery by this method with the greatest success, and particulars of ninety-five cases, concerning which notes were taken, are quoted in the table. In the earlier stages of acute dysentery this saturated soln tion of Epsom salts acts like a charm; fever, if present, disappears; mucus and blood are wanting in the stools, which become copious, fæculent, and bilious; the tenesmus ceases ; the patient's anxiety diminishes; the skin acts well, and sleep follows the administration of the first few doses. It is especially in the acute cases that sulphate of magnesia is so valuable; the more chronic the case becomes the less apparent are the advantages of this method of treatment. So utterly opposed to the accepted method of treativg acute dysentery is the use of a saturated solution of mag nesia sulphate that on several occasions, when suggesting its administration to colleagues in consultation over a severe case of acute dysenterv, the suggestion has been received with looks of alarm, deprecating shrugs of the shoulders, and remarks concerning the want of orthodoxy involved in such a method of treating the disease. The results furnished by this method of treatment have in most cases been so astonishing that $I$ feel it my duty to place on record my impressions regarding it. Personally $I$ have used it in the following manner:-A drachm of the saturated solution

2 A Practical Treatise on Materia Mediea and Therapentics, by Roborts Bartholow, M.A., M.D., LL.D. Fourth edition, 1832: London : H. K. Lewis. 
List of Cases of Acute Dysentery treatlid witi a Saturated Solution of Epsom Sals.

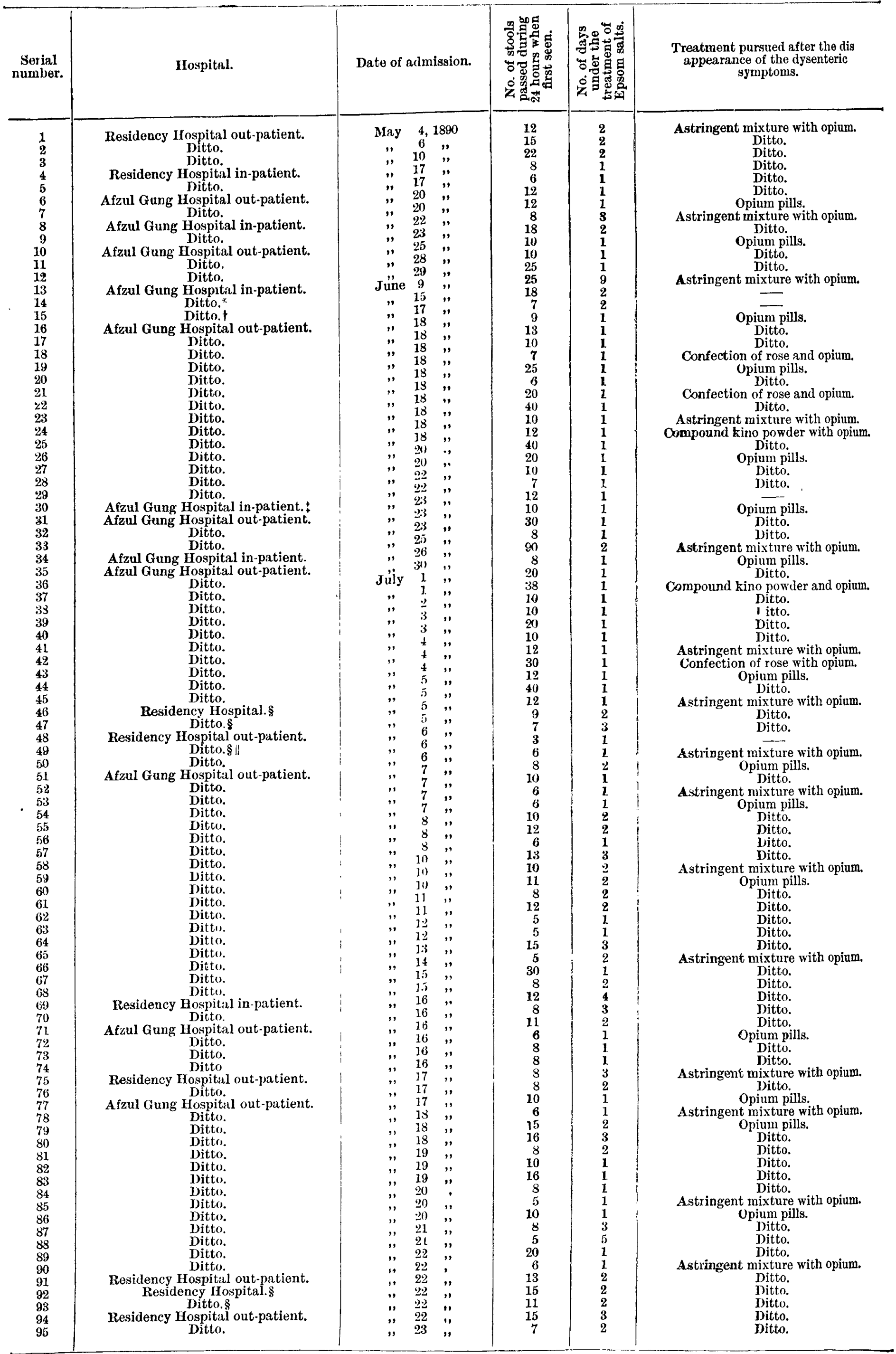

* This man was much emaciated and greatly debilitated on admisssion. 
with ten drops of dilute sulphuric acid have been given every hour or two until the stools have become copious, freculent, and free from blood and mucus, the temperature has fallen, and the pain and tenesmus have ceased. When the stools have become normal in colour and appearance, and the patient only passes two or three in the twentyfour hours, an ordinary astringent mixture of acid with laudanum or tincture of Indian hemp, or a pill containing extract of opium, is usually all that is necessary to complete the cure. It is, of course, imperative to diet the cases with great care. It is especially with reference to this method of treating acute dysentery as an alternative to the treatment of the disease by large doses of ipecacuanha that I am of opinion the value of a saturated solution of Epsom salts will in the future be found paramount. Its advantages over ipecacuanha may be summed up as follows: 1. It has no depressant action on the system. 2. It neither produces nausea nor vomiting. 3. It quiets and soothes the patient. 4. Its physiological action on the mucous membrane of the intestines in relieving hyperæmia is sound, and by this means it probably prevents the formation of ulcers within the gut, places those which may have already formed into a condition most favourable for their healing, preventing the acute inflammatory process and engorgement of the mucous membrane leading to the death of more tissue, and thus bringing about a cure. This part of India (the Deccan) may perlaps be correctly termed the home of dysentery, and typical severe cases of the acute variety of the disease are only too commonly met with. The annexed table of ninety-tive cases will serve to show the valuable pro. perties of Epsom salts in acute dysentery. These tabulated results of this method of treatment are the more valuable when it is known that the cases were in no way selected ones; that they nearly all occurred among the poorer class of patients who seek relief at the hospital, and that the vitality of many of them was at an exceedingly low ebb when they came under treatment. Out of the total of ninety-five three died. Two out of the three cases were at the time of their admission into hospital in a moribund condition. The resisting power of the poorer class of natives against such a disease as acute dysentery is much below that possessed by Europeans of the same class, and they succumb much more easily to its effects. In twentyseven cases of acute dysentery among Europeans that I have treated with a saturated solution of Epsom salts all have been successfully cured, and at some other time I intend to publish a short account of their cases. If this note is the means of directing the attention of other medical officers whose opportunities of meeting with cases of acute dysentery are greater than mine to this method of treatment I shall feel satisfied. If they will give the remedy a trial in acute cases, instead of using large doses of jpecacuanha, I have not the slightest doubt as to what their verdict will be. But, as was stated before, it is peculiarly in acute dysentery that the saturated solution of sulphate of magnesia will yield such excellent results. The more chronic the case the less likely is the remedy to prove of value. Hyderabad.

\section{OZ ENA AND SOME OTHER FORMS OF RHINITIS.}

BY W. SPENCER WATSON, F.R.C.S. ENG., SURGEON TO THE THROAT DEPARTMENT OF THE GREAT NORTHERN
HOSPITAL.

Pathology--After taking into consideration the descriptions of authors, and especially Krause's description of the microscopic sections of the mucous membrane made by him, and studying the clinical progress of cases under my own observation, I have come to regard the true atrophic rhinitis as a form of lupus, perhaps the lupus erythematodes of the English, modified and altered in its characters by the locality and tissues in which it has happened to commence. We have, as Krause has pointed out, disease of the glands, infiltration cells undergoing disintegration and fatty degeneration, and atrophic wasting of the tissues without ulceration. In all these particulars there seems to me a strong resenblance to the lupus of the skin without ulceration, as seen in lupus erythematodes. The effects, if any, of treatment, the obstinacy and chronicity of the malady, and the frequently phthisical family history, all suggest the probability of an alliance between ozæna proper and lupus.

Ozcenic odour. - Whatever may be the cause of the initial morbid lesion, the peculiar stench is due (according to Dr. Rohrer of "Zurich) to the presence of "putrid forms of bacilli" found in the secretions of fetid rhinitis, as also in those of fetid otorrhoea. In 14 cases of fetid rhinitis (out of a total of 24 cases of rhinitis, fetid and nonfetid) specimens examined yielded 56 times bacteria, 30 times cocei, and 26 bacilli. The cocci were found 6 times in pus and 24 in cultivations; the bacilli 5 times in pus, and 21 in cultivations. In the 10 non.fetid cases bacteria were demonstrated 19 times, cocci 8 , and bacilli 11 . They were found only in cultivations. Staphylococci were most often met with in the non-fetid cases; while monococci, diplococci, and bacilli of various forms were found in the fetid cases. Many kinds of odours were perceptible during the cultivations. In ozæna secondary putrid, carrion.like odours were noticed, and not unfrequently an aromatic odour like acetone or malic acid; sometimes odours reminding one of rotten lily petals and putrefying cheese. ${ }^{1}$ There is also a possibility of the odour being in some measure due to the butyric acid fermentation as suggested by Virchow. Whether the zoogloea bacilli and bacillus megaterium and forms of clostridia have any causal connexion with the special odour requires confirmation.

Diagnosis. - The treatment and diagnosis of ozena are mutually interdependent. Treatment in the form of douches and sprays must, as a rule, precede the diagnosis; and in the application of this preliminary treatment thoroughness and efficiency are essential factors. Take the case of a patient of, say, twelve years of age, who has bad for months or years a chronic obstructive rhinitis of both nostrils, with fetor, occasionally very pronounced, but with intervals of comparative freedom from the stench. No view of the interior of the nostrils can be obtained without a thorough cleansing with the douche. We may then inspect the parts. A wide atrophic state of the nasal fossæ may be revealed, and the fetor may remain unaffected, or only transiently relieved. There are no ulcerations, and on passing the probe no carious or necrosed bone or cartilage and no foreign body can be discovered. There is then little doubt that we have here a case of true ozæna. But in another case there may be no decided atropby of the membrane, no wasting of the turbinated bones (there may even be hypertrophy of the inferior turbinated on one or other side); so diseased bone, no ulceration, and no foreign body can be detected, and yet after the use of the douche the fetor rapidly returns, and offensive discharges and crusts continue to form as before. This case is probably one of commencing ozæna; the stage of the disease is so early, and the process so limited in extent, that there is nothing characteristic in the appearances of the mucous membrane. In such a case treatment would probably be successful in arresting the progress of the disease, and a hopeful prognosis might be given; while in the former case I should be inclined to regard the symptoms as only doubtfully curable, though certainly capable of palliation. In a third case, after free douching, simple congestion, with perhaps hypertrophy, may be demonstrated, and the fetor remains subdued for days (or weeks. Here there can be no question of true ozæna. In a fourth instance diseased bone or a foreign body may be discovered, and the diagnosis is then much facilitated. In all doubtfnl cases, however, much help may be afforded by the consideration of collateral evidenef, such as the family history, the existence or absence of similar affections in other members of the family, and the unsuccessful results or otherwise of previous treatment. There are two forms of rhinitis with fetor which must be distinguished carefully from true oznena-viz.,(1) chronic rhinitis, with caries or necrosis ; and (2) rhinitis caseosa of Cozzoline. To the former the term " ozæna" is applied by many authors, and especially by Rouge of Lausanne, who has met with a number of such cases, and treated them by a specially devised operation of his own. Apart from the fact that in these cases there will be no true atrophy of the mucous membrane, the history will lead to the suspicion of caries or necrosis, possibly a syphilitic taint or an injury of some kind being brought to light on inquiry. The existence of a piece of loose or carious bone, however, can only

1 The Morphology of the Bacteria found in the Lar and Nasom pharynx, by Dr. Rohrer of Zurich. 